\title{
A pre-post evaluation of an online career planning module on university students' career adaptability
}

\author{
Megan Teychenne ${ }^{1}$, Kate Parker ${ }^{1}$, Danielle Teychenne ${ }^{2}$, Shannon Sahlqvist ${ }^{1}$, Susie \\ Macfarlane $^{2}$ and Sarah Costigan ${ }^{3}$
}

megan.teychenne@deakin.edu.au; k.parker@deakin.edu.au; d.teychenne@deakin.edu.au; shannon.sahlqvist@deakin.edu.au; susie.macfarlane@deakin.edu.au; sarah.costigan@deakin.edu.au

Corresponding author: Megan Teychenne

${ }^{1}$ Deakin University, Geelong, Australia, Institute for Physical Activity and Nutrition (IPAN), School of

Exercise and Nutrition Sciences

2Deakin University, Burwood, Australia, Learning Futures

${ }^{3}$ Deakin University, Geelong, Australia, School of Exercise and Nutrition Sciences

\begin{abstract}
Indecisiveness and negative thinking regarding career pathways can hinder university students' career planning, motivation, and mental health. Students intending to enter the workforce after graduation therefore need to develop skills related to career adaptability (i.e. career planning, decision-making, problem solving/confidence and exploration), particularly since career planning and construction is linked to gaining employment. This study aimed to test the effectiveness of an online career planning module on students' career adaptability. The career-focussed online module, based on the constructs of Savickas' (2005) theory of career construction, and tailored to students' skills and interests, was developed and embedded into the University curriculum of a second-year exercise and public health-related unit. In 2018, 80 students completed the online module, along with pre- and post-intervention questionnaires assessing career adaptability elements including career planning, decision making, problem solving/confidence, and exploration. Dependent t-tests were conducted to assess differences in these measures pre- and post-intervention. Post-intervention, significant increases in career-planning strategies used $(\mathrm{t}(69)=5.45, \mathrm{p}<0.001)$, career planning concern $(t(69)=3.73, p<0.001)$, decision making (i.e. career path identification) $(t(70)=3.86, p<0.001)$, decision making confidence $(\mathrm{t}(65)=2.69, \mathrm{p}<0.01)$, and problem solving/confidence $(\mathrm{t}(65)=$ 2.16, $p=0.03$ ) were observed. Further, $80 \%$ of participants identified jobs at post-intervention not previously identified pre-intervention (exploration) and $71 \%$ of participants perceived improvements in confidence regarding job ideas/making career choices. Findings from this research indicated that completing a brief online career education module, tailored to an individual's skills and interests, improved all dimensions of the participating students' career adaptability. Further research utilising longer-term follow-up and randomised controlled trial designs are required to confirm the reliability and transferability of the findings.
\end{abstract}

Keywords: higher education, career planning, graduate employability, e-learning 


\section{Introduction}

Career planning and construction is an integral skill to develop, particularly for university students intending to enter the workforce after graduation. The employment landscape has significantly changed over the past decade, with a decline in the overall stability and security of work, particularly amongst young people (Carney \& Stanford, 2018). This is despite approximately half of young adults in Australia being tertiary educated (Organisation for Economic Co-operation and Development, 2018). The 2015 Graduate Destinations report showed that about one third of bachelor degree graduates in Australia were still seeking fulltime employment four months after graduation (Graduate Careers Australia, 2015), further highlighting a need for career planning and skill development to be better integrated into university courses. Negative career thoughts and indecisiveness regarding their career pathways can impact on students' mental and emotional health (i.e., leading to increased stress, anxiety, depression) (Fouad, 2007; Saunders, Peterson, Sampson Jr, \& Reardon, 2000) and further hinder career planning, motivation and decision making (Sampson, 2008). Therefore, it is important that students are supported in the career planning and decision making process during their time at university.

Developing practical and effective job planning and seeking behaviours has been linked to gaining employment (Kanfer, Wanberg, \& Kantrowitz, 2001). Universities hold a responsibility to provide opportunities for students to develop their career planning skills. One such approach is to embed career planning into the curriculum, which may be particularly important for students in broad vocational courses, such as health or exercise and sports science degrees (de Hollander, McGuckin, Sinclair, Barnett, \& Sealey, 2018), for which career paths may be more challenging to define. Although career education programs have been shown to result in improvements in career planning amongst high school students (Miles, 2008; SyedMohamad, 2005), few studies have examined the impact of such approaches for university students (Talib, Salleh, Amat, Ghavifekr, \& Ariff, 2015).

We previously designed a tailored, career-focused interactive online module for students studying at the undergraduate level in the areas of exercise science and health promotion (Teychenne et al., 2017), which included a number of features targeting the theoretical constructs from Savickas' theory of career construction (Savickas, 2005). The theory suggests that constructing a career is guided by an individual's vocational personality (i.e., careerrelated abilities, values, interests), life themes (i.e., career choice reflecting an individual's identity) and career adaptability (Savickas, 2005). The construct of career adaptability refers to the readiness to cope with predictable tasks (i.e. preparing for and/or participating in the role of the job) and unpredictable changes related to jobs and their conditions (Savickas, 1997). This construct was targeted by the module given it is more likely to be influenced by career education programs and/or strategies, and includes four key elements: career planning (i.e. utilising strategies to achieve career goals), decision-making (i.e. making choices about career paths to pursue), problem solving/confidence (i.e. confidence to plan, seek and achieve career goals), and exploration (i.e., investigating potential career choices) (Stringer, Kerpelman, \& Skorikov, 2011).

Previously, the perceived feasibility and acceptability of the career planning module was evaluated using a mixed methods design (Teychenne et al., 2017) and it was concluded that the online module was perceived to be a feasible and effective strategy to support university students in their career planning and job seeking behaviours prior to graduation. All students in the study $(n=22)$ reported that the module was user-friendly, engaging and informative. Qualitative data additionally indicated that many students reported that prior to completing the module, they had little idea or preference about their future career options, and therefore valued the module as it helped them to explore possible career choices and pathways, tailored to their own values, attributes and personal interests. Although the results of that pilot study

Teychenne, M., Parker, K., Teychenne, D., Sahlqvist, S., Macfarlane, S., \& Costigan, S. (2019). A pre-post evaluation of an online career planning module on university students' career adaptability. Journal of Teaching and Learning for Graduate Employability, 10(1), 42-55. 
were promising, the sample size and response rate was low and therefore generalisability was limited. Further, it is not known whether this online career planning and education module, developed according to Savickas' (2005) theory of career construction, was also effective for enhancing students' career adaptability. Therefore, the primary aim of this study was to test the effectiveness of an online career planning and education module on students' career adaptability (i.e. career planning, decision-making, problem solving/confidence and exploration).

\section{Methods}

\section{Setting}

The study was conducted at a large Victorian university, with four campuses and a high enrolment of off-campus (i.e. online) students.

\section{Design}

A brief career education intervention, utilising a tailored, online module developed specifically for physical activity and health students, was evaluated using a pre-test post-test design to assess the effectiveness of enhancing students' career adaptability. Participants completed online questionnaires immediately before and after engaging with the interactive online career planning module.

\section{Intervention delivery and components}

As part of scheduled course work during a two-hour seminar (tutorial) approximately mid-way through a teaching period in early 2018 , students undertaking a second level physical activity promotion unit were required to complete the career planning and education module. This was linked to a small assessment task completed during the final exam. The interactive module enabled students to explore graduate and post-graduate entry jobs relevant to the field of physical activity, exercise and health. A second level unit was selected as students study the unit mid-way through their degree, and they therefore have some foundation knowledge and may be thinking about their future employment. However they still have time to implement changes in response to their career education. This approach of 'front loading' university courses with career planning and experiences has been suggested to enhance retention and learning (The Study Group on the Conditions of Excellence in American Higher Education, 1984). The module was designed based upon the four dimensions of the 'career adaptability' construct of the theory of career construction (Savickas, 2005) (see Figure 1) and details of the development and features of the online module have been previously reported (Teychenne et al., 2017). In brief, the development of the module spanned 18-months. Systematic searches of career/job search websites were initially conducted by the researchers over a 12month period, identifying relevant jobs in the field. Video interviews were then conducted with professionals working in the jobs identified to provide further in-depth insight into the role. Key selection criteria were used to link skills and interest areas to each job and an algorithm was developed (i.e. a skill/interest area was scored either 1 [if relevant to a specified job] or 0 [if not relevant to a specified job]), enabling a ranking system. Savickas' theory of career construction (Savickas, 2005) was selected given that it targets improvements in flexibility and adaptability to cope with career/work-related challenges, which is reflective of the demands of the labour market, generally characterized by multiple transitions between job positions (i.e. non-linear career paths) (Langher, Nannini, \& Caputo, 2018; Savickas \& Porfeli, 2012). Table 1 presents a summary of strategies used to target each dimension of career adaptability.

Teychenne, M., Parker, K., Teychenne, D., Sahlqvist, S., Macfarlane, S., \& Costigan, S. (2019). A pre-post evaluation of an online career planning module on university students' career adaptability. Journal of Teaching and Learning for Graduate Employability, 10(1), 42-55. 


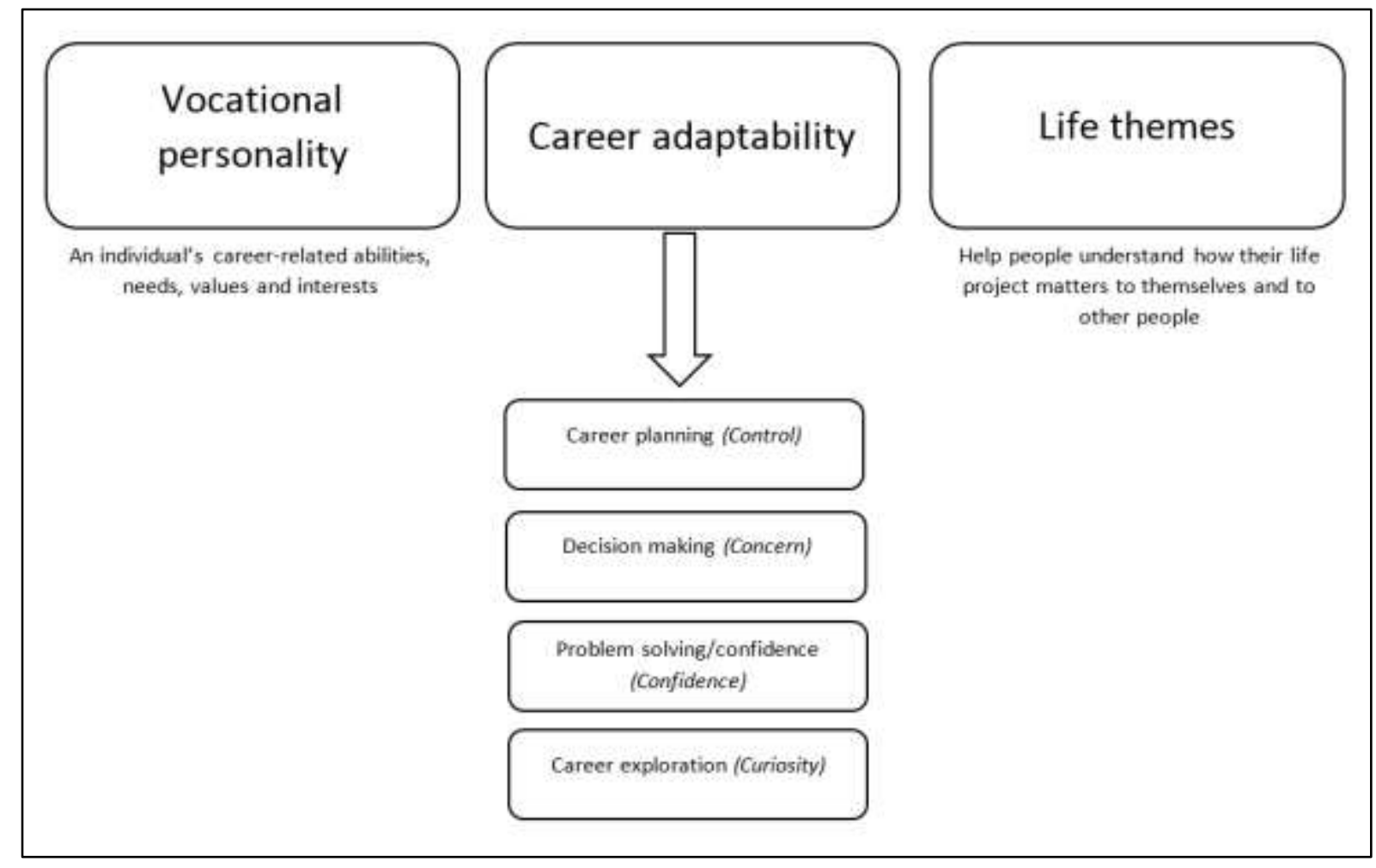

Figure 1: Theory of Career Construction (Savickas, 2005)

Table 1: Strategies Implemented in the Online Career Planning Module and Related Elements of Career Adaptability

\section{Strategy}

\section{Element of career adaptability}

A 'choose your own career adventure' quiz which helped guide students towards jobs based on their career interests, work-related skills and personal attributes.

A detailed overview of a selection of jobs $(n=23)$ in the area of physical activity, exercise and health.

Video interviews with professionals currently employed in the area of physical activity, exercise and health.

Key selection criteria for each job identified, which could be completed, printed out and used as notes for future job applications and/or job interview preparation.

A job interview simulator including interview questions tailored to the jobs identified.
- Career planning

- Decision making

- Career exploration

- Career planning

- Career exploration

- Career exploration

- Problem solving/confidence

- Problem solving/confidence

Students independently worked their way through the module, first completing a series of questions designed to determine the students' (a) area of interest, (b) setting in which they would like to work and, (c) the population group they would like to work with (see Table 1). Following this, students were presented with a comprehensive set of personal qualities and work related skills and for each, were asked to choose the three to five most relevant to them. 
Based on their responses, students were then presented with a series of jobs that they could learn more about by reading a short summary and watching video interviews with professionals in the relevant field. Students could then go through the mock process of applying and interviewing for their chosen job by addressing key selection criteria and participating in a simulated interview. Approximately 40 minutes of class time was dedicated to completing the online module, which was reported by tutors to be a sufficient length of time for all students to complete it. Students could (and were encouraged to) continue to access the module outside of class time via the unit's online site to explore other career choices.

\section{Participant recruitment}

This study was approved by Deakin University's Human Ethics Advisory Group (Faculty of Health). All students currently enrolled in the second year core physical activity promotion unit were eligible to participate in the study. The brief intervention was available to all students enrolled in the unit across three campuses and those enrolled off-campus using the University's online teaching platform. Participants were recruited via two avenues. In the first instance, an invitation to participate, including details of the study in plain language, instructions to access the pre- and post-intervention questionnaires and a link to the interactive online module was posted on the online unit site. Secondly, students attending the week 7 seminar (on-campus and off-campus) were provided with the same information by the seminar instructor. Students consented to participate via an electronic form prior to completing the baseline online questionnaire. The chance to win one of two $\$ 100$ gift cards was offered to participants as compensation for their time.

\section{Measures}

Participants completed baseline and post-intervention online questionnaires immediately before and after engaging with the career-focused interactive online module (see Table 2).

\section{Demographic information}

Participant demographic characteristics were collected via the baseline questionnaire. Participants reported their sex, age, whether they had children living with them, mature-aged student status (e.g. enrolled in their university course after 21 years of age), international student status, currently in workforce, in workforce prior to this year, and if applicable, number of years in the workforce.

\section{Career planning}

- Career planning strategies: Participants' self-reported use of strategies for career planning was assessed at baseline and post-intervention using a seven-item scale developed for the current study. Participants identified which of the following strategies they had used to develop their career readiness: a) completing key selection criteria for relevant jobs, b) undertaking practice job interviews, c) identifying personal strengths required for gaining a career in the field, d) searching for jobs, e) other. For each item participants responded Yes $=1$ or No $=0$. The total number of strategies used was then summed to generate an overall score ranging from 0-5.

- Career planning concern: The concern construct sub-scale (Savickas \& Porfeli, 2012) was used at baseline and post-intervention to assess participants' self-reported ability to plan and prepare for their future career. The scale uses the common stem "how strongly have you developed each of the following abilities..." with response options ranging from 1 Not strong to 5 Strongest, for the following items: (a) thinking about what my future will be like, (b) realising that today's choices shape my future, (c) preparing for the future, (d) becoming aware of the educational and career choices that I must make, (e) planning how to achieve my goals, and (f) concerned about my career. Ratings for each item were summed to create a score from 6- 
36. The concern construct sub-scale has shown good internal consistency reliability $(\alpha=0.83)$ (Savickas \& Porfeli, 2012).

Table 2: Timing and Measures of Elements of Career Adaptability

\begin{tabular}{|c|c|c|c|}
\hline $\begin{array}{l}\text { Element of Career } \\
\text { Adaptability }\end{array}$ & Item & Baseline & $\begin{array}{l}\text { Post- } \\
\text { intervention }\end{array}$ \\
\hline Career planning & $\begin{array}{l}\text { Career planning strategies } \\
\text { Career planning concern }\end{array}$ & $\checkmark$ & $\checkmark$ \\
\hline Decision making & $\begin{array}{l}\text { Career path identification } \\
\text { Decision making confidence }\end{array}$ & $\checkmark$ & $\checkmark$ \\
\hline $\begin{array}{l}\text { Problem- } \\
\text { solving/confidence }\end{array}$ & $\begin{array}{c}\text { Problem solving/confidence } \\
\text { Skills awareness }\end{array}$ & $\checkmark$ & $\checkmark$ \\
\hline Exploration & Career identification & $\checkmark$ & $\checkmark$ \\
\hline Student perceptions & $\begin{array}{c}\text { Confidence regarding job ideas and career } \\
\text { choices } \\
\text { Degree to which the module helped career } \\
\text { adaptability }\end{array}$ & & $\checkmark$ \\
\hline
\end{tabular}

Decision making

- Career path identification: Participants' self-reported clarity on identifying a career path relevant to their course of study was assessed at baseline and post-intervention using one item which was developed for the current study. The item asked participants to indicate their current level of clarity regarding their future career path on a four-point scale from 1 I have no idea of what career path and job I will pursue to 4 I have a very clear idea of what career path and job I will pursue.

- Career decision making confidence: Participants' self-reported confidence in career decision making was assessed at baseline and post-intervention using a 4-item modified version of the 'Career Decision Making Self-efficacy Scale' (Betz, Klein, \& Taylor, 1996). The scale uses the common stem How much confidence do you have that you could... with response options as follows: 1 No confidence at all to 5 Complete confidence. Sample item: identify some reasonable major or career alternatives if you are unable to get your first choice. The mean of the 4-items was calculated to generate an overall career decision making confidence score (range: 4-20), higher scores indicated greater confidence in career decision making. The reliability of 'Career Decision Making Self-efficacy Scale' has been found to be acceptable $(\alpha=0.94)$ (Betz et al., 1996).

\section{Problem solving/confidence}

- Career problem solving confidence: Participants' self-reported career problem solving confidence was assessed at baseline and post-intervention using a 3-item scale from the 'Career Decision Making Self-efficacy Scale' (Betz et al., 1996). The scale used the common

Teychenne, M., Parker, K., Teychenne, D., Sahlqvist, S., Macfarlane, S., \& Costigan, S. (2019). A pre-post evaluation of an online career planning module on university students' career adaptability. Journal of Teaching and Learning for Graduate Employability, 10(1), 42-55. 
stem How much confidence do you have that you could... with response options ranging from 1 No confidence at all to 5 Complete confidence, to rate the following items: a) accurately assess your abilities, b) describe the job duties of the career/occupation you would like to pursue, and c) successfully manage the job interview process. To generate an overall career problem confidence score, the three items were summed (range: 5-15). The full scale has been found to be reliable ( $\alpha=0.94)$ (Betz et al., 1996).

- Skills awareness. In order to assess the impact of the intervention on students' awareness of the skills required to enhance their graduate employability, participants were asked both at baseline and post-intervention: What skills/areas do you need to develop to enhance your chances of gaining employment in jobs relevant to your course? Skills mentioned at both pre and post-intervention were scored zero, and each new skill cited post-intervention was scored 1. Scores were summed to create an overall skills awareness improvement score.

\section{Exploration}

To assess career exploration, participants were asked at baseline and post-intervention to identify as many possible career choices that their university degree could potentially lead to (an open-ended question). All jobs identified at both time points were reviewed by a researcher. To evaluate whether career exploration had improved (i.e., knowledge of potential career choices), at post-intervention each job re-cited was scored zero, and each new job cited was scored 1 . Scores were summed to create an overall exploration score.

\section{Student perceptions of the career education module}

To evaluate participants' perceptions of the impact of the module on confidence, following the intervention participants reported whether their confidence regarding job ideas and career choices had changed, with response options of: improved (1), no change (0), reduced $(-1)$. Participants then selected from a list of six possible options (including 'other' where another response option could be provided by the participant), the factors to explain the change. Additionally, participants rated the degree to which the module helped them: a) explore different career options; b) make choices about their career (strongly agree (5) to strongly disagree (1)). Responses for those two questions were dichotomised into two categories (agree and disagree).

\section{Data analysis}

All statistical analyses were completed using STATA 15 (StataCorp, 2017). Demographic characteristics of the sample were identified including: sex (\% female), age (mean, SD) mature age status (\% yes), International student (\% yes), marital status (\% married, de facto/living together, divorced, never married), children living with you (\% yes), currently in workforce (\% yes), in workforce prior to this year (\% yes), years in workforce (mean, SD) and the course they were currently enrolled in (\% Bachelor of Exercise and Sport Science, Bachelor of Exercise and Sport Science/Bachelor of Business (Sport Management), Bachelor of Health Science). To detect if responses to the career planning, decision-making and problem solving/confidence scales significantly differed pre- and post-intervention, dependent t-tests (non-parametric equivalent) were conducted.

To examine change in students' awareness of skills required to enhance graduate employability (problem solving), participant responses were assessed qualitatively to determine whether they changed after completing the online module and if so, in what way. Similarly, to examine change in 'career exploration', the number of career choices identified by participants at each time-point were summed and assessed qualitatively to determine whether any new jobs options were identified during the post-test questionnaire. Frequencies of participants' post-intervention perceptions of changes in career decision making confidence and exploration were also calculated. 


\section{Results}

Of the 345 students enrolled in the unit, a total of $105(30 \%)$ participants completed the baseline (T1) questionnaire and of those $80(23 \%)$ also completed the post-intervention (T2) questionnaire. Table 3 provides an overview of characteristics of participants who completed both T1 and T2 surveys and were included in the final analytical sample. Although not explicitly assessed, there were no ad hoc reports of harmful intervention effects.

Table 3: Demographic Characteristics of Participants in the Final Analytical Sample $(n=80)$

\begin{tabular}{lc}
\hline & $\mathrm{N}(\%) /$ Mean (SD) \\
\hline Male & $40(50 \%)$ \\
Female & $40(50 \%)$ \\
Age (years) & $21.23(5.78)$ \\
Mature aged student (yes) & $15(19 \%)$ \\
International student (yes) & $3(4 \%)$ \\
Children living with you (yes) & $5(6 \%)$ \\
Currently in the workforce (yes) & $50(63 \%)$ \\
In workforce prior to this year (yes) & $49(61 \%)$ \\
Years in workforce & $5.4(6.5)$ \\
Course currently enrolled in: & \\
Bachelor of Exercise and Sport Science & $63(79 \%)$ \\
Bachelor of Exercise and Sport Science/Bachelor of \\
Business
\end{tabular}

\section{Career planning}

Table 4 presents the results from dependent t-tests. Participants reported an increase of 0.63 in the number of career-planning strategies utilised after completing the career planning module $(95 \% \mathrm{Cl}, 0.40$ to 0.86$), \mathrm{t}(69)=5.45, \mathrm{p}<0.001$. There was an increase in career planning concern scores by a mean of 1.44 from baseline to post-intervention $(95 \% \mathrm{Cl}, 0.67$ to 22.21); $\mathrm{t}(69)=3.73, \mathrm{p}<0.001$. 
Table 4: Dependent t-test Analyses Examining Means of Career Adaptability Constructs at Baseline (T1) and Post-intervention (T2)

\begin{tabular}{lcrrr}
\hline \multicolumn{1}{c}{ Construct } & Item/question & $\begin{array}{c}\text { T1 } \\
\text { Mean (SD) }\end{array}$ & $\begin{array}{c}\text { T2 } \\
\text { Mean (SD) }\end{array}$ & p \\
& Number of strategies used & $1.67(0.93)$ & $2.30(1.18)$ & $<\mathbf{0 . 0 0 1}$ \\
\hline Career planning & Career planning concern & $21.07(3.70)$ & $22.51(3.95)$ & $<\mathbf{0 . 0 0 1}$ \\
Decision making & Career path identification & $2.80(0.86)$ & $3.06(0.79)$ & $<\mathbf{0 . 0 0 1}$ \\
$\begin{array}{l}\text { Decision-making self-efficacy } \\
\text { scale }\end{array}$ & Decision making confidence & $14.65(0.36)$ & $15.23(0.35)$ & $<\mathbf{0 . 0 1}$ \\
Problem-solving/confidence & Problem solving/confidence scale & $10.58(2.24)$ & $10.86(2.18)$ & $\mathbf{0 . 0 3}$ \\
\hline
\end{tabular}

\section{Decision making}

Career path identification increased (mean difference $=0.25 ; 95 \% \mathrm{Cl}, 0.12$ to 0.38 ) from baseline to post-intervention; $\mathrm{t}(70)=3.86, \mathrm{p}<0.001$. Participants' decision making confidence also increased (diff $=0.58 ; 95 \% \mathrm{Cl}, 0.15$ to 1.00 ) after completing the intervention; $\mathrm{t}(65)=2.69$, $\mathrm{p}<0.01$.

\section{Problem solving/confidence}

Problem solving/confidence increased after completing the intervention (mean difference = $0.38 ; 95 \% \mathrm{Cl}, 0.03-0.73 ; \mathrm{t}(65)=2.16, \mathrm{p}=0.03)$. Further, at post-intervention $58 \%$ of participants reported they needed to develop at least one new skill to enhance their chance of gaining employment. The most frequently reported new skills included communication, interpersonal skills and teamwork.

\section{Exploration}

Participants identified an average of four jobs in the field during the baseline questionnaire. At post-intervention, $80 \%$ of participants $(n=54)$ identified jobs that they hadn't identified at baseline. Of these, the average number of new jobs identified was three.

\section{Student perceptions}

Post-intervention, $70.6 \% \quad(n=48)$ of participants reported that their confidence regarding knowledge of job ideas and making career choices had improved after completing the career planning module (see Table 5). Of those who reported an increase in confidence, the three most frequently cited reasons included; the module providing new ideas of jobs (81\%), now having a better understanding of what the job involves (67\%), and the module helped them to identify the jobs they don't want to do (40\%). Three participants reported a reduced level of confidence after the intervention, with two out of three stating that they have a better understanding now of what the job involves and that the module clarified their misconceptions. When asked whether the module helped them make choices about their future career, $78 \%$ agreed. The majority (90\%) of participants agreed that the module helped them to explore different career options. 
Table 5: Frequencies of Post-intervention Perceptions Regarding Career Confidence $(n=68)$

\begin{tabular}{lcccccc}
\hline & \multicolumn{2}{c}{ Improved } & \multicolumn{2}{c}{$\begin{array}{c}\text { No } \\
\text { change }\end{array}$} & \multicolumn{2}{c}{ Reduced } \\
\hline Confidence about job ideas/making career choices & $48(70.6 \%)$ & $17(25.0 \%)$ & $3(4.4 \%)$ \\
\hline Reasons why confidence had changed or not & Yes & No & Yes & No & Yes & No \\
The tool provided new job ideas & 39 & 9 & 5 & 12 & 1 & 2 \\
The tool helped me identify jobs I don't want & 19 & 29 & 8 & 9 & 0 & 3 \\
I now know exactly what job I want to do & 7 & 41 & 2 & 15 & 0 & 3 \\
I have a better understanding of what the job involves & 32 & 16 & 2 & 15 & 2 & 1 \\
The tool clarified misconceptions & 14 & 34 & 1 & 16 & 2 & 1 \\
'Other' & 0 & 48 & 7 & 10 & 2 & 1 \\
\hline
\end{tabular}

${ }^{*}$ tool $=$ career planning and education module

\section{Discussion}

This study examined the effectiveness of a brief intervention utilising an online career planning and education module for improving students' career adaptability. The module specifically aimed to enhance the four key elements of 'career adaptability' comprising career planning, decision making, problem solving/confidence, and exploration. The overall findings of this study indicated that one exposure to the career planning and education module resulted in small and significant improvements in all elements of career adaptability. Our findings provide evidence for the benefits of embedding career planning into the curriculum via an online module, for enhancing career adaptability in university students.

\section{Career planning}

Career planning incorporates the use of active strategies to achieve one's career goals and the ability to prepare for a future career (Savickas, 2013). After completing the online career planning module, participants reported having used a greater number of active career planning strategies and an increase in career planning concern (i.e. concern about future career planning and preparation) was also reported. These findings suggest the brief intervention provided students with opportunities to practice using career planning strategies and to plan how their career goals could be achieved, which are important skills for future job seeking. For instance, features of the online module provided opportunities for participants to complete key selection criteria, undertake practice job interviews and search for jobs in the area of their degree, which students may not previously have been exposed to. Our findings are in line with previous studies which have found improvements in career planning after participating in career intervention programs (Miles, 2008; Syed-Mohamad, 2005; Talib et al., 2015). For example, one study investigating the effectiveness of a career education and development module in Malaysian community college students ( $n=122$; mean age: 20.41(0.73)), facilitated by a counsellor during nine two-hour classes, found significant increases in career planning ability in the intervention group in comparison to controls (Talib et al., 2015).

The results of our brief intervention are promising, given previous studies highlight the importance of university students developing strategies for planning career pathways rather than identifying a specific job, as most individuals experience multiple career transitions during

Teychenne, M., Parker, K., Teychenne, D., Sahlqvist, S., Macfarlane, S., \& Costigan, S. (2019). A pre-post evaluation of an online career planning module on university students' career adaptability. Journal of Teaching and Learning for Graduate Employability, 10(1), 42-55. 
their working life (Langher et al., 2018). It is important to note, however, that career planning is an iterative and ongoing process that should be regularly revisited throughout university courses (and beyond) in order to foster career resilience (Waddell et al., 2015). Therefore, the impact of an interactive module - such as the one described in this study - should be evaluated within the context of an entire degree in which repeat exposure to career planning is available.

\section{Decision making and decision making confidence}

Results of this study demonstrate that completion of the online career planning module improved students' clarity on career path identification and their decision making confidence. Students' perceptions of the module support these findings and suggest that engaging with the online module was useful for providing new career ideas, and for developing a better understanding of what certain careers involve. Interestingly, it appears that the module also helped students identify those jobs they do not wish to pursue. Findings from previous studies investigating career decision making and decision making confidence are inconsistent. For instance, a two year experimental study of undergraduate students $(n=133$ ) found that engaging in a career course intervention was effective for improving career decision making self-efficacy in comparison to a quasi-control group, however the intervention did not reduce career decision making difficulties (Reese \& Miller, 2010). On the contrary, a meta-analytic review of nine studies investigating career intervention effectiveness found higher effect sizes for interventions when focusing on reducing career indecision rather than on increasing career decision-making self-efficacy (Langher et al., 2018).

\section{Problem solving/confidence}

This study found that there was a small increase in problem-solving/confidence after completing the online career planning module. Further, after completing the module, more than half of participants were able to identify at least one new skill that they needed to develop to enhance their chance of gaining employment (including communication, interpersonal skills and teamwork). The 'problem solving/confidence' construct of career adaptability refers to efficacy, industriousness (i.e. diligence) and the process of finding solutions to somewhat complex issues (i.e. problem solving) (Savickas, 2013). Our findings suggest that the strategies used within the module to address this element (i.e. writing responses to key selection criteria and experiencing the 'mock' job interview) may be sufficient to increase this ability in students. However, given the difference in problem solving/confidence scores between baseline and follow-up was quite small (mean difference $=0.38$ ), additional strategies may be needed to exhibit a larger change. One such strategy may be to provide the opportunity within the module for students to reflect on their experience of these processes. Alternatively, it may be that further enhancement of problem solving/confidence may require greater engagement with the module (rather than only accessing the module once as was the case in this brief intervention) and therefore longer-term studies may be required to determine effectiveness.

\section{Exploration}

Findings showed that the module enhanced students' ability to identify new career choices related to their university degree (i.e. exploration), which was further supported by students' perceptions after accessing the module, with most agreeing it helped them to explore different career options. This is particularly important for degrees with broad vocational outcomes (e.g. exercise and sport science, or health science) in which many students have a limited understanding of relevant jobs in the field. Although only one aspect of 'exploration' was measured, with other components such as inquisitiveness, risk taking, and taking an inquiring approach (Savickas, 2013) still needing to be assessed in greater depth, findings were encouraging. Previous research amongst students studying exercise and sports science-

Teychenne, M., Parker, K., Teychenne, D., Sahlqvist, S., Macfarlane, S., \& Costigan, S. (2019). A pre-post evaluation of an online career planning module on university students' career adaptability. Journal of Teaching and Learning for Graduate Employability, 10(1), 42-55. 
related degrees has shown that providing students with career-related experiences early in their degree (e.g. work placement) can increase awareness of potential careers that may be pursued after graduation (de Hollander et al., 2018). Although not discounting the value of work placement experience, our findings suggest that students may gain career exploration skills via an online module, which could either be used to supplement the experience of work placement, or utilised when work placement is not able to be offered in existing courses.

\section{Strengths and limitations}

The limitations of this study include a low (30\%) response rate, which may limit the generalisability of findings. Also self-report measures were used which can be influenced by recall difficulties and bias. Further, not all measures used to assess constructs (e.g. exploration and career planning strategies) were previously validated/reliability tested, which could increase the possibility of measurement error. Given that the brief intervention was conducted during a single class, students were time restricted and therefore it is not known if accessing the module for a longer period of time (or taking it multiple times) would result in a greater increase in career adaptability. Although the sample size was sufficient to detect associations in the overall sample, the study was not powered to analyse dichotomised data based on demographic characteristics of the sample (e.g. whether or not participants were mature aged). Finally, given that students completed the follow-up questionnaire immediately after working through the module, it is not known whether students actually used the skills and knowledge gained to seek employment, and whether doing so enhanced the likelihood of success.

A key strength is the intervention (pre-post-test) study design with immediate follow-up, which provided a good indication of the short-term effectiveness of the module on elements of career adaptability. The retention rate $(76 \%)$ was high, indicating that once students consented they were likely to complete the study. Key strengths of the intervention include targeting students at a mid-point of their degree, embedding Savickas' theory of career construction throughout the intervention and evaluation (Savickas, 2005), and that the intervention itself was 'brief' (i.e. delivered once in one seminar/tutorial). Given that most units / courses have a great level of content to cover and therefore may not perceive that they have time to address career education, this study has shown that just one module in one unit can enhance career adaptability.

\section{Conclusion}

Given that developing effective job planning and seeking behaviours is linked to the likelihood of obtaining employment (Kanfer et al., 2001) it is imperative that university students are equipped with these skills prior to graduation. Implementing an online career planning module, tailored to students' interests and skills, and embedding this into the curriculum, may enhance career adaptability, which could potentially lead to improvements in graduate employability (Koen, Klehe, \& Van Vianen, 2012). Further research with a control group, longer follow-up periods, and investigating effects of repeated exposure to the tool, are needed to confirm findings. 


\section{References}

Betz, N. E., Klein, K. L., \& Taylor, K. M. (1996). Evaluation of a short form of the career decisionmaking self-efficacy scale. Journal of Career Assessment, 4(1), 47-57.

Carney, T., \& Stanford, J. (2018). The dimensions of insecure work: A factbook. Manuka, ACT: The Australia Institute, Centre for Future Work.

de Hollander, C., McGuckin, T., Sinclair, K., Barnett, F., \& Sealey, R. (2018). Front loading the curriculum: Early placement experiences enhance career awareness and motivation for students with diverse career options. Student Success, 9(2), 39-47.

Fouad, N. A. (2007). Work and vocational psychology: Theory, research, and applications. Annual Review of Psychology, 58, 543-564.

Graduate Careers Australia. (2015). Graduate Destinations 2014. Melbourne: Graduate Careers Australia.

Kanfer, R., Wanberg, C. R., \& Kantrowitz, T. M. (2001). Job search and employment: A personality-motivational analysis and meta-analytic review. Journal of Applied Psychology, 86(5), 837-855.

Koen, J., Klehe, U.-C., \& Van Vianen, A. E. (2012). Training career adaptability to facilitate a successful school-to-work transition. Journal of Vocational Behavior, 81(3), 395-408.

Langher, V., Nannini, V., \& Caputo, A. (2018). What do university or graduate students need to make the cut? A meta-analysis on career intervention effectiveness. Journal of Educational, Cultural and Psychological Studies (ECPS Journal) 17, 21-43.

Miles, J. (2008). The impact of a career development programme on career maturity and academic motivation. University of Fort Hare, London.

Organisation for Economic Co-operation and Development. (2018). Population with tertiary education. Retrieved from https://data.oecd.org/eduatt/population-with-tertiaryeducation.htm

Reese, R. J., \& Miller, C. D. (2010). Using outcome to improve a career development course: Closing the scientist-practitioner gap. Journal of Career Assessment, 18(2), 207-219.

Sampson, J. P. (2008). Designing and implementing career programs: A handbook for effective practice: National Career Development Association.

Saunders, D. E., Peterson, G. W., Sampson Jr, J. P., \& Reardon, R. C. (2000). Relation of depression and dysfunctional career thinking to career indecision. Journal of Vocational Behavior, 56(2), 288-298.

Savickas, M. (1997). Career adaptability: An integrative construct for life-span, life-space theory. Career Development Quarterly, 45(3), 247-259.

Savickas, M. (2005). The theory and practice of career construction. In S. D. Brown \&. R. W. Lent (Eds.), Career developmenet and counseling: Putting theory and research to work (pp. 42-70). Hoboken: John Wiley and Sons.

Savickas, M. L. (2013). Career construction theory and practice. In S. D. Brown \& R. W. Lent (Eds.), Career development and counseling: Putting theory and research to work (2nd ed., pp. 147-183). Hoboken, NJ: John Wiley \& Sons.

Savickas, M. L., \& Porfeli, E. J. (2012). Career Adapt-Abilities Scale: Construction, reliability, and measurement equivalence across 13 countries. Journal of Vocational Behavior, 80(3), 661673.

StataCorp. (2017). Stata Statistical Software: Release 15. College Station, TX: StataCorp LLC.

Stringer, K., Kerpelman, J., \& Skorikov, V. (2011). Career preparation: A longitudinal, processoriented examination. Journal of Vocational Behavior, 79(1), 158-169.

Syed-Mohamad, S. (2005). Effectiveness of career planning module on motivation to learn, Learning skills and the ability to plan a career low achievers. Unpublished Doctoral Dissertation, Universiti Kebangsaan Malaysia, Bangi.

Talib, J. A., Salleh, A., Amat, S., Ghavifekr, S., \& Ariff, A. M. (2015). Effect of career education module on career development of community college students. International Journal for Educational and Vocational Guidance, 15(1), 37-55. 
Teychenne, M., Sahlqvist, S., Teychenne, D., Macfarlane, S., Dawson, P., \& Costigan, S. (2017). The development of a tailored, career-focused interactive online learning tool for physical activity and health students: A pilot study. Journal of Teaching and Learning for Graduate Employability, 8(1), 60-73.

The Study Group on the Conditions of Excellence in American Higher Education. (1984). Involvement in learning: Realizing the potential of American higher education. Washington, DC: National Institute of Education.

Waddell, J., Spalding, K., Canizares, G., Navarro, J., Connell, M., Jancar, S., . . \& Victor, C. (2015). Integrating a career planning and development program into the baccalaureate nursing curriculum: Part I. Impact on students' career resilience. International Journal of Nursing Education Scholarship, 12(1), 163-173. 